\title{
O SUJEITO NA HISTÓRIA E NA PSICANÁLISE: uma discussão possível
}

\author{
Ismael Fenner* \\ Susana Marília Barbosa Galvão**
}

\section{Resumo}

Este artigo sobre o sujeito na história e na psicanálise parte da compreensão da articulação do conceito de sujeito pelos campos da história, da filosofia e da psicanálise e o sentimento do medo nos diferentes momentos da história. Foi um estudo de revisão bibliográfica com o objetivo de apresentar uma reflexão sobre os sujeitos inseridos nos campos da ciência e da psicanálise. Enquanto a historiografia trabalha com a cisão sequencial entre passado e presente, a psicanálise inclui o passado no presente como bem demonstra a ideia freudiana de recalcamento e seu retorno.

Palavras-chave: História. Medo. Psicanálise

\section{INTRODUÇÃO}

Este artigo propõe a noção de sujeito como um conceito-processo numa construção fundamentada nos acontecimentos de cada época. O comprometimento da relação que o sujeito estabelece com o mundo que o cerca é também representado pelo medo.

Inicia-se apresentando a teoria do medo a partir de contextos históricos e ampliando a reflexão com as contribuições da Nova História Cultural para a discussão do tema.

De acordo ao que se tem em cada época o medo compromete a relação que o sujeito estabelece com o mundo que o cerca.

A psicanálise traz suas contribuições, dialogando com os conhecimentos teóricos da história, levando em conta as demarcações, para a partir daí conhecer melhor estes sujeitos na revivência de um lugar/tempo, na possibilidade de inventar a si mesmo. Por

\footnotetext{
* Diretor Geral da Facultad Interamericana de Ciencias Sociales-Fics. Asunción-PY

E-mail: ismaelfenner@hotmail.com

** Coordenadora Acadêmica da Facultad Interamericana de Ciencias Sociales-Fics- Asunción-PY

E-mail: susi.barbosa@hotmail.com
} 
ser atemporal, a psicanálise não opera com um conceito específico, embora seja fundamental para entender a construção do sujeito.

\section{O MEDO EM DIFERENTES ÉPOCAS}

A história do medo é muito antiga, a qual acometia tanto os indivíduos isoladamente, quanto a coletividade e às civilizações.

O medo é socialmente construído a partir do que a cultura expõe e se diversifica de acordo a época.

O medo sofreu um processo de internalização segundo Bauman (2008) tendo começado com o Cristianismo quando a figura do demônio foi apresentada aos fieis.

[...] Os homens de Igreja apontaram e desmascararam esse adversário dos homens. Levantaram o inventário dos males que ele é capaz de provocar e a lista de seus agentes: os turcos, os judeus, os heréticos, as mulheres e especialmente, as feiticeiras. (DELUMEAU, 2009, p. 23).

A investigação do historiador francês parte não do "medo" como se fosse algo dado e objetivo, mas do papel do medo na história, de modo particular no Ocidente préindustrial, procurando compreender as dinâmicas sociais nas quais ele se produz e as suas consequências.

O medo foi difundido na cultura ocidental como elemento inerente a natureza humana, sendo possível aprisionar mentes despreparadas para lidar com o medo, onde qualquer pessoa estaria sujeita a possessão, tornando o ser humano como agente transmissor do mal (ENGELS, 2001).

Sintomas psicológicos foram desencadeados pois passaram a buscar uma introspecção para se purificar e combater o pecado, para se livrarem do medo do inferno, dos castigos de Deus.

Traduz-se que o medo na Idade Média, tinha sido o período mais marcante da história, onde o mesmo era utilizado para que se mantivesse o controle da Coroa e da Igreja.

Delumeau (2009) em suas obras-primas escritas entre 1978 e 1989 sobre o medo e a necessidade de segurança captaram a marca do presente. O lugar comum é o lugar dos humildes medrosos. 
Entre os séculos XIV e XVI, o medo começa a ser superado traduzido pela metáfora " o cavaleiro sem medo" digno deste título deve decifrar os perigos por amor da glória e de sua dama. Na abordagem de Dalumeau (2009), quanto mais se arrisca aos combates desiguais daquela época mais se conquista a honra.

No Século XVII La Bruyére compartilha a ideia de que os camponeses, artesãos e criados representam uma massa desencorajada por não poderem buscar a fama. A incompatibilidade entre romance e teatro naquela época, representava ao mesmo tempo o universo social e moral: o da valentia individual dos nobres e o do medo, coletivo dos pobres.

$\mathrm{Na}$ época da Renascença, os homens de posses agiam de modo que os camponeses tivessem medo. "Com a Revolução Francesa, conquistaram pela força o direito a coragem. Mas o novo discurso idealista copiou o antigo e seguiu a tendência de camuflar o medo para exaltar o heroísmo dos humildes" (DELUMEAU, 2009, p.117).

Segundo Delumeau (2009) o sentido sobre as modificações do medo varia com a história tanto como ele se apresenta quanto a sua concepção. Medo e covardia não são sinônimos. Mas é preciso questionar se a Renascença não foi marcada por uma tomada de consciência mais clara das variadas ameaças que pesam sobre os homens no combate.

Pensa-se que aqueles cavaleiros impulsivos, habituados as guerras e aos duelos são menos conscientes dos perigos em relação ao combate dos soldados do século XX.

O arquétipo do cavaleiro sem medo é realçado pelo contraste de um coletivo sem coragem (DELUMEAU, 2009). O medo do inimigo tornou-se regra.

Aos arqueiros era dado vinho antes do combate para cegá-los diante do perigo.

Na época da Renascença ou seja, "os homens no poder agem de modo a que, o povo essencialmente os camponeses tivessem medo". (DELUMEAU, 2009, p. 17).

De acordo com Dalgalarrondo (2008), médico psiquiatra, o medo é uma reação a uma situação de perigo, seja ela real ou imaginária. O medo patológico é denominado fobia que segundo ele, “[...] são medos desproporcionais e incompatíveis com as possibilidades de perigo real oferecidos pelos desencadeantes de situações fobígenas". (DALGALARRONDO, 2008, p. 171). 
Não se atendo a sua definição conceitual básica, é importante uma leitura da subjetividade do sujeito em relação a sua contextualização histórica e cultural.

\section{HISTÓRIA E PSICANÁLISE}

A experiência psicanalítica segundo Chemama (2007) é uma experiência de palavra, para liberação da fala na clínica no âmbito privado. A história mostra que nem sempre este sujeito era reconhecido.

Quando se pensa a história da história a preocupação dos historiadores, o sentido histórico, a passagem da modernidade para a pós-modernidade, são representados na historiografia. No cristianismo, a história esteve dominada pela providência divina.

Tendo em mente que o conceito é um constructo, a primeira metafísica que se desenvolve do mundo clássico da Grécia até o Renascimento, precisa construir saber. Pensa-se o mundo como objeto e que há um sujeito das coisas do mundo.

[...] Na segunda metafísica, com as descobertas de Copérnico, o mundo volta a ser multiplicidade sem centro: é a ideia do infinito [...] a questão passa a ser o conhecer: o homem a que ao mesmo tempo tudo pode e nada é, é o que põe em jogo a sua liberdade e a sua destinação no surgimento do conceito de subjetividade. (PACHECO, 1996, p. 63).

Tem-se então o sujeito da Filosofia mas nem sempre foi assim e por isto se diz que se tem fraturas do presente.

No nascimento do Ocidente segundo Pacheco (1996) entendido como contexto cultural, a origem do conceito de sujeito somente o diferencia dos animais e dos deuses numa situação ambígua: matava o animal para comê-lo e como prova de coragem, incorporava os seus traços nos ritos praticados.

O mito foi apresentado como expressão da origem do homem, do animal, situados em um tempo passado. Recorre-se a eles para explicar uma teoria ou realidade.

Ainda com Pacheco (1996) surge posteriormente a figura do sábio, capaz de ultrapassar as suas limitações corporais para encarnar o delírio do saber (P

latão), Sócrates, o último Xamã e o primeiro filósofo, o modelo perfeito de homem. 
Entende-se que a experiência mais próxima da individualidade ainda está até Platão e a fundação da metafísica. Este sujeito, indivíduo iluminado, se estende até o fim da Idade Média ou o princípio do Renascimento.

De acordo com Bitencourt (2017) quem inaugura o pensamento moderno no Século XVII é Descartes, com o conceito de subjetividade no discurso do pensamento contemporâneo, como procedente da verdade.

Cabe aqui retomar a Idade Média, para reafirmar que neste período vivia-se num mundo considerado ordenado e finito, onde todas as coisas tinham o seu lugar organizadas numa tendência para serem procuradas e nela repousarem. Aqui o homem encontra-se na sua morada. (KOYRÉ, 1992).

Com a modernidade, surge o descompasso na ordem cósmica, o universo entendido como infinito pelo advento da ciência, influenciado pela matematização, representado por Descartes e pela metafísica. Neste espaço agora aberto, foi introduzido o discurso científico. O homem aqui não é o senhor de sua morada. A ciência não dá lugar ao homem, mas ao sujeito, o qual foi recolhido pela psicanálise.

Foi a ciência moderna que introduziu um corte nessa esfera que antes era ancorada pela ideia de perfeição.

A Psicanálise foi buscar a noção de sujeito na tradição metafísica. Freud constrói a sua primeira tópica de sujeito como origem e posteriormente, advindo de um polo pulsional e não se trata aqui do sujeito da filosofia contemporânea.

O lugar do "eu penso" referenciado por Descartes não é o mesmo do "eu sou", momento em que se distancia de Freud. Para Freud há pensamento sem pensador, ou seja o isso pensa antes de ter certeza.

Para Descartes (APUD PACHECO, 1996, p. 71):

[...] o pensamento é a certeza da existência, o sujeito é porque pensa, este pensar como consciência de si [...] para Freud o pensamento é inconsciente, logo onde eu não sou como consciência é onde penso e sou como sujeito do inconsciente, do desejo.

Quando Descartes inaugura o conceito de uma certeza que se manteria por inteiro no eu penso da cogitação, “[...] poder-se-ia dizer que seu erro é crer que isso é um saber. Dizer que ele sabe alguma coisa dessa certeza. Não é fazer do eu penso um simples ponto de desvanecimento". (LACAN, 1964/1988, p. 212). 
Partindo de um ponto comum - a certeza inaugural e fundadora de Descartes e Freud que emerge sob a forma de um pensamento sem qualidade -, o campo da ciência e o da psicanálise tomam direções diametralmente opostas, pois a primeira resguarda o saber e não se ocupa da verdade, enquanto que a segunda a recoloca em cena, aquela Outra.

Há o sujeito, que está aí esperando desde Descartes.

Ouso enunciar, como uma verdade, que o campo freudiano não seria possível senão certo tempo depois da emergência do sujeito cartesiano, por isso que a ciência moderna só começa depois que Descartes deu seu passo inaugural. É desse passo que depende que se pudesse chamar o sujeito de volta para casa, no inconsciente [...]. É preciso, para compreender os conselhos freudianos, partir desse fundamento de que é o sujeito que é chamado - o sujeito da origem cartesiana (LACAN, 1964/1988, p. 49-50).

Lacan (apud PACHECO, 1996, p. 71) aproxima em três pontos o sujeito cartesiano do sujeito que ele próprio apresenta: "não há certeza sem dúvida (sem o significante do Outro), não há eu penso sem exclusão do saber (é a disjunção saber/verdade) e o tempo deste sujeito que é pontual feito de instantes, penso, existo e não penso, logo existo)".

\section{O MEDO, O SUJEITO E A ATUALIDADE}

Freud (1930-1936/2010), em seu clássico texto Mal-estar na civilização, já alertara de que uma das fontes de sofrimento humano sobrevém a partir das relações intersubjetivas, considerando-a muito mais penosa quando comparava a decadência do corpo frente à passagem do tempo e a influência do mundo externo da qual não se tem nenhum controle.

Mas se o medo é um sentimento próprio da natureza humana, seria plausível falar sobre ele com mais familiaridade. De acordo com Dunker (2015) ele 'pode ser entendido como um sentimento inquietante que se tem diante de perigo ou ameaça ou ainda uma ansiedade diante de uma sensação desagradável, da possibilidade de fracasso. "No processo de socialização, a interpretação do medo é muito básica, tanto para pensar mecanismos de defesa da espécie, quanto de ligação com o outro".

De acordo com os estudos de Freud (1915/1985), o medo pode ter uma fase de indeterminação, que é a angústia. Assim, anular o medo fingindo que ele não existe, ou seja, não observando o que causa aquele sentimento, pode levar a quadros de depressão, 
ansiedade e outros distúrbios emocionais. Angústia, ansiedade, fobia, ódio, medo, pânico, são representantes do medo, ou seja, seu representante semântico é muito rico. Freud elege a angústia como tema central. As diversas categorias do medo podem ser lembradas no curso da história.

Freud foi o primeiro a introduzir a angústia no vocabulário da psicopatologia. Freud se referiu a neurose de angústia (FREUD, /1985) como um recorte do vocabulário do medo, designando um mal estar psíquico e físico com sensações físicas desagradáveis.

Pelos efeitos clínicos da $1^{\text {a }}$ Guerra Mundial (FREUD, 1916-1917, 1920) Freud propôs a divisão de medos e angústias. A angústia é abstraída do objeto e o pavor é o efeito de um perigo marcado pela surpresa, ou seja, de acordo com Freud o ser humano se protege do pavor por meio do medo de angústia.

As neuroses traumáticas, neuroses de guerra fornecem o modo explícito de uma manifestação de pavor e articulação da angústia e do medo particularmente nítida na fobia.

Dentre as experiências vividas, ganha espaço os seus contextos a partir de uma linguagem que é pessoal mas também pública das formas variadas para se entender e experimentar o medo.

De certa forma, atualmente o medo tem sido elemento normatizado da sociedade, estabelecendo padrões e controlando as pessoas com variadas roupagens.

Pensando em como a sociedade foi construída, cercada de medos e interesses, é considerável se pensar nos dias atuais como as pessoas estão interagindo com a realidade atual.

Com a sociedade moderna e pós moderna ou líquida como afirma Bauman (2008) e outros psicanalistas e sociólogos, tem produzido um certo mal-estar. A profissão docente em seus aspectos relacionais e subjetivos tem sido motivo de preocupação para os estudiosos.

Delumeau (2009) ao retratar o tema sobre o medo vem de encontro ao momento atual que os professores estão vivendo neste cenário dramático com a pandemia do coronavírus. 
As mudanças no processo e na organização da rotina de trabalho, do isolamento social, as condições de trabalho improvisadas e jornadas extenuantes, são fatores impregnados de medos e incertezas.

Pereira (2016), ao identificar essas mudanças que afetam direta e indiretamente a escola e o professor, nota que aí reside também uma singularidade, certo modo particular, e não universal, com o qual cada professor responde a essas demandas dentro de um contexto de vulnerabilidade psíquica, social e histórica.

No âmago de sua investigação, Pereira analisa a perda da autoridade docente e o que há em jogo, desde a escola até à universidade, sob a forma de padecimentos psíquicos, que ora fazem os professores sofrerem, ora os fazem reclusos ou os levam a identificar-se com o próprio padecimento.

De acordo com Pereira (2018, p.01):

\begin{abstract}
$\mathrm{Na}$ atualidade, observamos uma constatação pertinente, a qual se coaduna com a perspectiva de Freud: por motivos de confrontos com os alunos e as inúmeras dificuldades vivenciadas em sala de aula, muitos professores têm recebido licença médica e, outros, afastados das suas atividades laborais das escolas.
\end{abstract}

As pesquisas atuais assinalam e denunciam os novos rumos e desafios para aqueles que se ocupam da tarefa de educar, dita impossível, levando em consideração a premissa freudiana.

Segundo a premissa freudiana a angústia não opera sem objeto mas é preciso lembrar que este é um objeto perdido porque o que a provoca é a urgência da presença do que a própria presença. A angústia é a falta por estar ligada ao momento separador de constituição do objeto. A angústia é antes falta da falta que constitui o apoio do desejo para o sujeito.

A partir desta afirmativa, entende-se que a fobia mostra como o medo trata a angústia.

O medo é algo ambivalente. "É ao mesmo tempo alguma coisa que o impele a avançar e alguma coisa que o puxa para trás; é alguma coisa que faz de você um ser duplo e que, quando você o exprime diante de um personagem junto de quem você quer dar mostras de ter medo, põe você a cada instante na postura de reflexo. Tudo gira em volta de um termo: o temor a Deus. Lacan demarca essa báscula à volta da passagem do zelo para a fidelidade.

Para Bulhões (2010, p. 21), o medo é “[...] uma expressão visível da manifestação da angústia que, por sua vez, relaciona-se a uma vivência subjetiva, a um conflito psíquico". Ao 
ampliar o conceito, Botelho (2010, p. 33) delineia que o medo é a percepção das representações de mundo, "[...] determinadas por signos e associações ao que se sente medo"

Historiografia e Psicanálise dialogam no espaço e na memória de maneiras diferentes. Para Certau (2011) a psicanálise reconhece esta ligação onde um reproduz o outro com certas ambiguidades.

Já a história considera essa relação segundo o modelo da sucessividade (um depois do outro), da correlação (maior ou menor grau de proximidade), do efeito (um segue o outro) e da disjunção (um ou o outro, mas não os dois ao mesmo tempo) (CERTEAU, 2011, p. 73).

Desta forma, Freud utiliza a história para compreender e desenvolver seu pensamento, onde demonstra haver uma aproximação entre psicanálise e história pela via terapêutica. De certa maneira, o trabalho que a história e a psicanálise fazem é orientar o presente pela interpretação do passado.

O mito é temporal concomitante ao passado, presente e futuro porque supõe-se algo que contribuiu para a história presente. A apropriação da história pelo sujeito foi marcada por contradições e acontecimentos que a partir do originário se conhece o real.

\section{CONSIDERAÇÕES FINAIS}

Considerando o medo e sua passagem pela história, fica evidente que cada época de acordo aos acontecimentos retrata comportamentos diversos das pessoas. $\mathrm{O}$ medo na civilização ocidental, vivido pelas imagens diabólicas, aquelas representativas do juízo final, hoje é projetado a partir dos terrores morais, pelos impactos de uma pandemia que aterroriza e ameaça a vida. Uma avalanche de informações, reais ou imaginárias, invadem a vida psíquica dos sujeitos.

Alcançar a subjetividade deste sujeito no mundo contemporâneo é sem dúvida um desafio.

Todo e qualquer vivido em cada época, no entendimento da psicanálise, tende a retornar à consciência. Neste sentido, importa lembrar que o passado está no presente, pois nem tudo desaparece do psiquismo.

Se for pensado somente pela via da história, pelo sujeito da consciência filosófica, há uma distância entre o estudo daquilo que foi vivido. Este sujeito que vive a história na atualidade, foi invadido por uma quantidade de energia que rompe as barreiras de proteção psíquica. Mas este mesmo sujeito é aquele da psicanálise marcado e movido pela falta e incompleto. 


\section{REFERÊNCIAS}

BAUMAN, Zygmunt. Medo líquido. Rio de Janeiro: Zahar. Tradução de Carlos Alberto Medeiros, 2008.

BITENCOURT, Joceval Andrade. Descartes e a invenção do sujeito. $1^{\mathrm{a}}$ ed. Paulus, São Paulo, 2017

BOTELHO, Thatiany Lídia Moura. Visão sistêmica e perceptiva da pobreza no imaginário do medo pós-moderno: reflexos espaciais na cidade do Recife, 2010

BULHÕES, Luciana Berto Daher. Experiências maternas frente à continência dos medos infantis, 2010. 157f. Dissertação (Mestrado) - Curso de Psicologia, Faculdade de Ciências e Letras, Universidade Estadual Paulista, Assis, 2010.

CHEMAMA, R.; VANDERMERSCH, B. Dicionário de Psicanálise. Trad. Francisco Settineri e Mario Fleig. São Leopoldo: Unisinos, 2007.

DALGALARRONDO, Paulo. Psicopatologia e semiologia dos transtornos mentais. Porto Alegre, RS: Artmed, 2008.

DE CERTEAU, Michel. A escrita da História. Forense Universitária: Rio de Janeiro, $3^{\text {a }}$ Ed, 1987/2011.

DELUMEAU, Jean. História do medo no ocidente 1300-1800: uma cidade sitiada. São Paulo: Companhia das Letras, 2009. Tradução de Maria Lucia Machado.

DUNKER, Christian. Mal-estar, sofrimento e sintoma: uma psicopatologia do Brasil entre muros. Boitempo Editorial: São Paulo, 2015.

ENGELS, Friedrich; MARX, Karl. O manifesto do partido comunista. Porto Alegre: L\&PM, 2001.

FREUD, Sigmund. O mal-estar na cultura. Porto Alegre, 2010. L\&PM. Tradução de Renato Zwick.(texto original publicado entre 1930/1936)

FREUD, S. (1985). Obras completas. Buenos Aires: Amorrortu. (Originalmente publicado em 1915).

FREUD, S. (1976). conferências introdutórias sobre psicanálise. conferência XXV. In S. Freud, Edição standard brasileira das obras psicológicas completas de Sigmund Freud (Vol. 16). Rio de Janeiro: Imago, 1996 (Trabalho original publicado em 1916/1917)

KOYRÉ, A. (1992). Considerações sobre Descartes. Lisboa: Editorial Presença. (Trabalho original publicado em 1963)

LACAN, J. (1965/1998). A ciência e a verdade. In J. Lacan, Escritos (p. 855-892). Rio de Janeiro: Jorge Zahar Editor. (Trabalho original publicado em 1965)

LACAN, J. (1988). Seminário. Livro 11: os quatro conceitos da psicanálise. Rio de Janeiro: Jorge Zahar. (Originalmente publicado em 1964) 
PACHECO, Olandina, M. C. A. Sujeito e singularidade- ensaio sobre a construção da diferença, Jorge Zahar: Rio de Janeiro, 1996. 